\title{
Metoda Baru Untuk Menghitung Tingkat Konsistensi pada Tes Pauli \& Kraepelin
}

\author{
Sigit Haryadi; Salma Huda California \\ Pebruari 2018
}

\section{Paper DOI: 10.17605/OSF.IO/QHT8J}

Sitasi: Haryadi, S., \& California, S. H. (2018, March 14). Metoda Baru Untuk Menghitung Tingkat Konsistensi pada Tes Pauli \& Kraepelin. Retrieved from osf.io/preprints/inarxiv/qht8j

\begin{abstract}
Abstrak
Pada makalah ini, diusulkan suatu modifikasi dari pengukuran tingkat konsistensi kepribadian seseorang pada Tes Pauli \& Kraepelin yang terdapat pada bidang psikologi, yaitu dengan menggunakan rumus yang dibuat pada bulan April 2016, oleh Sigit Haryadi, dan dinamakan sebagai "the Harmony in Gradation" atau "Haryadi Index". Tujuan dari usulan ini karena rumus eksisting hanya menggunakan nilai rata-rata dari simpangan, yang menyebabkan ada kemungkinan bahwa hasil pengukuran konsistensi pada orang - orang yang faktanya adalah berbeda tingkat konsistensinya akan dianggap memiliki tingkat konsistensi yang sama, di sisi lain, metoda yang diusulkan akan lebih akurat dan presisi dalam hal memberikan penilaian tingkat konsistensi kepribadian seseorang.
\end{abstract}

\section{Perhitungan Tingkat Konsistensi Kepribadian Manusia pada Tes Pauli \& Kraepelin menggunakan "Indeks Haryadi"}

Emil Kraepelin adalah seorang psikiater akhir abad 19, yang menciptakan alat tes psikologi yang untuk mendapatkan informasi untuk mendiagnosa gangguan otak manusia berupa Alzheimer dan Dementia. Lalu, pada tahun 1938, Richard Pauli, Wilhelm Arnold, dan Vanmethod memperbaharui tes Kraeplin menjadi suatu "check method". Kemudian, Pauli menyempurnakan kembali, sehingga memungkinkan hasil test dapat ditafsirkan menjadi suatu data tentang kepribadian manusia. Saat ini test ini dinamakan sebagai test Pauli \& Kraepelin, dan mengukur Speed, Accuracy, Consistency, dan Endurance saat seseorang menghitung soal matematika penjumlahan sederhana, lalu menafsirkannya menjadi ukuran kepribadian manusia yang menjalani tes. Waktu yang dibutuhkan oleh seseorang untuk melakukan tes Pauli ini adalah 60 menit dengan kurun waktu per 3 menit, jadi semuanya ada 20 kurun waktu, tetapi khusus untuk pengukuran konsistensi, yang digunakan adalah hanya hasil tes selama 16 kurun waktu, yaitu pada kurun waktu ke-3 sampai ke-18. 
Makalah ini hanya mengusulkan modifikasi pada pengukuran skor konsistensi pada tes Pauli \& Kraepelin, yang oleh psikolog akan ditafsirkan menjadi informasi mengenai kestabilan emosi manusia.

Tanpa menggunakan ilmu matematika yang rumit, dapat dibuktikan bahwa metoda eksisting mengandung kelemahan. Sebagai contoh, ada dua orang yang memiliki nilai tes pada kurun waktu ke 3 sampai ke18 sebagai berikut: $\mathrm{A}=\{5,7,5,7,5,7,5,5,7,7,5,5,5,7,7,7\}$ dan $\mathrm{B}$ $=\{4,8,6,6,6,4,8,4,8,6,6,6,4,8,6,6,4,8\}$. Maka, dengan menggunakan rumus eksisting, concistensy score dari A dan B adalah sama, karena keduanya memiliki simpangan rata-rata yang sama. Padahal, secara instuisi seharusnya A dinilai lebih konsisten dibanding B, karena B menghasilkan banyak nilai yang terlalu kecil dan terlalu besar dibandingkan nilai rata-rata. Selain itu, skor yang didapatkan oleh A dan B menggunakan metoda eksisting adalah terlalu tinggi.

Makalah ini mengusulkan suatu metoda pengukuran dari skor konsistensi pada tes Pauli \& Kraepelin, dengan menggunakan rumus yang dibuat pada bulan April 2016, oleh Sigit Haryadi, dan dinamakan sebagai "Indeks Haryadi”, sebagai alternative menggantikan metoda eksisting, dimana penggunaan "Indeks Haryadi" akan lebih baik karena dalam rumusnya sekaligus mengandung "the Harmony" dan "the Gradation, di sisi lain, rumus eksisting dari Tes Pauli \& Kraepelin hanya mengandung salah satu unsur, yaitu "the Gradation".

Pada contoh perhitungan di atas, akibat rumus eksisting yang hanya memperhitungkan gradasi pada nilai- nilai dari 16 kurun waktu tes, maka A dan B oleh metoda eksisting dianggap memiliki konsistensi yang sama, padahal seharusnya harmoni antar nilai juga diperhitungkan, seperti yang akan dilakukan oleh metoda di makalah ini, maka metoda baru akan memberikan skor konsistensi A yang lebih tinggi dibanding B.

Rumus "Harmony in Gradation" dituliskan sebagai berikut:

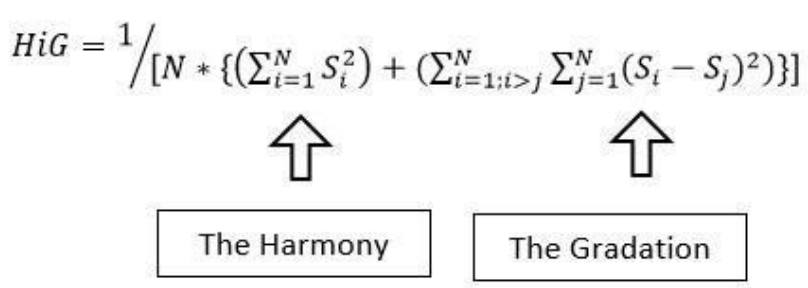

Dimana: HiG adalah "Harmony in Gradation" dari suatu variabel acak (atau suatu himpunan) yang memiliki populasi sampel (atau subset) $=\mathrm{N}$, dan Si adalah "the Share" dari tiap-tiap sampel (atau subset) = perbandingan antara kekuatan atau nilai dari masing-masing sampel (atau subset) dengan kekuatan total dari variable random (atau himpunan). 
Contoh-contoh rumus Indeks Haryadi atau Harmony in Gradation adalah sebagai berikut: (a) untuk suatu variable acak (atau himpunan) yang memiliki dua sampel (atau subset): HI(2), (b) untuk suatu variable acak (atau himpunan) yang memiliki tiga sampel (atau subset): HI(3), (c) untuk suatu variable acak (atau himpunan) yang memiliki empat sampel (atau subset): HI(4).

$$
\begin{aligned}
& \mathrm{HI}(2)=1 /\left[2\left\{\mathrm{~S}_{1}^{2}+\mathrm{S}_{2}{ }^{2}+\left(\mathrm{S}_{2}-\mathrm{S}_{1}\right)^{2}\right\}\right] \\
& \mathrm{HI}(3)=1 /\left[3\left\{\mathrm{~S}_{1}^{2}+\mathrm{S}_{2}{ }^{2}+\mathrm{S}_{3}{ }^{2}+\left(\mathrm{S}_{2}-\mathrm{S}_{1}\right)^{2}+\left(\mathrm{S}_{3}-\mathrm{S}_{1}\right)^{2}+\left(\mathrm{S}_{3}-\mathrm{S}_{2}\right)^{2}\right\}\right] \\
& \mathrm{HI}(4)=1 /\left[4\left\{\mathrm{~S}_{1}{ }^{2}+\mathrm{S}_{2}{ }^{2}+\mathrm{S}_{3}{ }^{2}+\mathrm{S}_{4}{ }^{2}+\left(\mathrm{S}_{2}-\mathrm{S}_{1}\right)^{2}+\left(\mathrm{S}_{3}-\mathrm{S}_{1}\right)^{2}+\left(\mathrm{S}_{4}-\mathrm{S}_{1}\right)^{2}+\left(\mathrm{S}_{3}-\mathrm{S}_{2}\right)^{2}+\left(\mathrm{S}_{4}-\mathrm{S}_{2}\right)^{2}+\left(\mathrm{S}_{4}-\mathrm{S}_{3}\right)^{2}\right\}\right]
\end{aligned}
$$

\section{Kalkulator Internet}

Untuk mempermudah pemahaman pada metoda ini, akan dibuatkan suatu "kalkulator internet", yaitu suatu website yang menyediakan kolom isian, dimana kita dapat mengisikan nilai -nilai dari peserta tes, lalu mendapatkan hasil perhitungan dari indeks konsistensi. Tapi kalkulator tidak membatasi pengujian yang memiliki 16 sampel pengukuran, seperti yang terjadi pada tes Pauli \& Kraepelin yang asli, tetapi kita diperbolehkan memasukan jumlah sample pengukuran yang lebih kecil atau lebih besar dari 16. Fasilitas ini disiapkan untuk antisipasi bila ada psikolog yang ingin melakukan tes dengan waktu tes yang kurang atau lebih dari 1 jam. Dan, dijamin metoda baru ini akan tetap akurat untuk berapapun ukuran sampel.

Kalkulator internet yang akan dibuat ada di alamat website http://sigitharyadi.net/ lalu di klik link "Consistency Test".

\section{Penjelasan Cara Perhitungan}

a) Pertama, dihitung share dari suatu sample pengukuran $=\mathrm{Si}=$ (nilai suatu sample pengukuran dibagi dengan jumlah nilai seluruh sample pengukuran).

b) Lalu, dihitung indeks konsistensi menggunakan rumus " Indeks Haryadi" berikut ini:

$$
H I=\frac{1}{\left[N^{*}\left\{\sum_{i=1}^{N} S_{i}^{2}+\sum_{i=1}^{N} \sum_{j=1}^{N}\left(S_{i}-S_{j}\right)^{2}\right\}\right]} ; i>j
$$

c) Lalu tentukan tingkat konsistensi sebagai berikut:

i. Indeks Haryadi antara 0,95 sampai dengan 1,00 adalah bersesuaian dengan "Sangat Konsisten".

ii. Indeks Haryadi antara 0,75 sampai dengan 0,94 adalah bersesuaian dengan "Konsistensi baik.

iii. Indeks Haryadi antara 0,60 sampai dengan 0,74 adalah bersesuaian dengan "Hampir Kurang Konsisten". 
iv. Indeks Haryadi antara 0,50 sampai dengan 0,59 adalah bersesuaian dengan "Kurang Konsisten.

v. Indeks Haryadi adalah kurang dari 0,50 adalah bersesuaian dengan Tidak Konsisten”.

\section{Catatan}

Agar lebih memahami konsep "Harmony in Gradation" atau "Indeks Haryadi" yang menjadi roh dari kalkulator ini dipersilahkan untuk membaca makalah-makalah dan buku-buku yang terdapat di daftar pustaka sebagai berikut.

\section{References}

[1] Sigit Haryadi. (2017). Haryadi Index and Its Applications in Science of Law, Sociology, Economics, Statistics, and Telecommunications. Penerbit Elex Media Komputindo. Jakarta. ISBN: 978-602-02-9895-5.

[2] Sigit Haryadi. (2017). Indeks Haryadi dan Penerapan di Ilmu Hukum, Sosiologi, Ekonomi, Statistik, dan Telekomunikasi. Penerbit Elex Media Komputindo, Jakarta. ISBN: 978-602-02-9896-2

[3] Sigit Haryadi. (2016). Haryadi Index for Competition, Equality and Correlation Evaluation. Penerbit Lantip Safari Media, Bandung, Indonesia. ISBN: 978-60273231-3-2

[4] Sigit Haryadi. (2016). Haryadi Index untuk Evaluasi Kompetisi, Kesetaraan dan Korelasi. Penerbit Lantip Safari Media, Bandung, Indonesia. ISBN: 978-602-732313-1

[5] GarudaDivine. (2018, March 13). Paulin - Pauli \& Kraepelin Test Simulator APK. Available at https://apkpure.com/paulin-pauli-kraepelin-testsimulator/com.garudadivine.paulin

[6] HR News Ruang Informasi \& Diskusi para HR. (2018, March 13). Available at http://psikohr-news.blogspot.co.id/2013/01/pauli-test.html

[7] Haryadi, S. (2018, March 6). Calculation the Equity Level of an Internet Service. Retrieved from osf.io/uzcmq

[8] Haryadi, S. (2018, March 6). Perhitungan Tingkat Pemerataan Layanan Internet. Retrieved from osf.io/preprints/inarxiv/rgct3

[9] Dyah Rakhma Ariyanti; Sigit Haryadi. (October 2017). Analysis of Harmony In Gradation Index on 5G Cellular Network Quantitative Analysis. The 11th International Conference on Telecommunication Systems, Services, and Applications, At Lombok, Indonesia.

[10] Haryadi, S. (2017, November). Probabilitas Statistik Untuk Insinyur. Researchgate. DOI: 10.13140/RG.2.2.14304.58885

[11] Haryadi, S. (2018, February 1). Indeks Haryadi dan Prospeknya Untuk Menjadi Suatu "Formula of Everything (versi 31 Desember 2017). Retrieved from osf.io/zex45

[12] Haryadi, S. (2018, February 1). KALKULATOR untuk membuat Regresi Linier Tanpa Intersep. Retrieved from osf.io/emvs7

[13] Haryadi, S. (2018, February 1). Kalkulator Untuk Mengukur Tingkat Kompetisi di suatu Industri, dengan menggunakan rumus Indeks Haryadi. Retrieved from osf.io/fy7zu 
[14] Haryadi, S. (2018, February 17). Calculation the Competition Levels between Students in Class and the Relation to the Teacher or Lecture Fairness in Teaching. Researchgate. DOI: 10.13140/RG.2.2.30359.06569

[15] Haryadi, S. (2018, February 17). Perhitungan Tingkat Kompetisi antar Murid atau Mahasiswa di Kelas dan Kaitannya Dengan Keadilan Guru atau Dosen Dalam Mengajar. Retrieved from osf.io/a894w

[16] Haryadi, S. (2018, February 22). Equality Correlation Calculation. Researchgate. DOI: 10.13140/RG.2.2.22068.76168

[17] Haryadi, S. (2018, February 22). Kalkulator Untuk Menghitung Korelasi Kesetaraan. Retrieved from osf.io/preprints/inarxiv/7r9jy

[18] Haryadi, S. (2018, February 24). Calculation of "Channel Cavity" on Data Communications. Equality Correlation Calculation. Research gate. DOI: 10.13140/RG.2.2.30536.01288

[19] Haryadi, S. (2018, February 24). Perhitungan "Rongga Kanal” pada Komunikasi Data. Retrieved from osf.io/preprints/inarxiv/y3wcg

[20] Haryadi, S. (2018, February 28). Ikhtisar Organisasi Regulasi Telekomunikasi. Retrieved from osf.io/preprints/inarxiv/g9m3k

[21] Haryadi, S. (2018, February 7). Statistik Terapan: Pengujian Regulasi \& Kebijakan Telekomunikasi. Retrieved from osf.io/3pkfw

[22] Haryadi, S. (2018, January 25). Chapter 1. The Concept of Telecommunication Network Performance and Quality of Service. Retrieved from osf.io/mukqb

[23] Haryadi, S. (2018, January 26). Chapter 2 of Network Performance and Quality of Service: Determination of Key Performance Indicator (KPI). Retrieved from osf.io/preprints/inarxiv/6gtnd

[24] Haryadi, S. (2018, January 26). Chapter 3 of Network Performance and Quality of Service: Technical Measurement of a Mobile Network Performance and Quality of Service. Retrieved from osf.io/q4wsz

[25] Haryadi, S. (2018, January 30). Basic Calculation of the Network's Availability and Reliability (Chapter 4 of Network Performance and Quality of Service). Retrieved from osf.io/preprints/inarxiv/z5mwq

[26] Haryadi, S. (2018, March 1). Kebijakan Lisensi Telekomunikasi. Retrieved from osf.io/7wbjf

[27] Haryadi, S. (2018, March 5). Performance Measurement of Internet Service. Retrieved from osf.io/9nsw3

[28] Haryadi, S., \& Riani, W. (2018, March 5). METODE PENETAPAN TARIF PAJAK PENGHASILAN YANG BERKEADILAN. Retrieved from osf.io/preprints/inarxiv/ayg58

[29] Nie Levin Kusuma Adiatma ; Sigit Haryadi. (2017, October). Comparison of the Haryadi Index with Existing Method in Competition, Equality, Fairness, and Correlation Level Calculation Case Study: Telecommunication Industry. The 11th International Conference on Telecommunication Systems, Services, and Applications, At Lombok, Indonesia.

[30] Sigit Haryadi. (2017). Calculation of the Mobile Communication Competition using Haryadi Index. DOI: 10.13140/RG.2.2.15634.25280

[31] Sigit Haryadi. (2017). Harmony in Gradation and its prospects as the Formula of Everything, First edition of posts: December 31, 2017. Researchgate. DOI: 10.13140/RG.2.2.19309.08169

[32] Sigit Haryadi. (2017). the Equality Correlation Method. Researchgate. DOI: 10.13140/RG.2.2.10443.80169. 
[33] Sigit Haryadi. (2017). the Non-Intercept Linear Regression Method. Researchgate. DOI: 10.13140/RG.2.2.18721.71522

[34] Sigit Haryadi. (2017). The. Fairness over Inequality Index: Unfairness is Disaster - a notebook of Sigit Haryadi. Researchgate. DOI:

10.13140/RG.2.2.34379.49449.

[35] Sigit Haryadi. (2017, December). Calculator for Measurement the Competition Index \& Level. Researchgate. DOI: 10.13140/RG.2.2.23626.26568

[36] Sigit Haryadi. (2017, December). Calculator for non-intercept linear regression. Researchgate. DOI: 10.13140/RG.2.2.15761.94562.

[37] Sigit Haryadi. (2017, January). Calculation of the Income Equality Levels between Regions using the Haryadi Index. Researchgate. DOI:

10.13140/RG.2.2.36605.77282

[38] Sigit Haryadi. (2018, February). Applied Statistics for Assessment of the Regulation and Policy: case study in Telecommunication Industry. DOI: 10.13140/RG.2.2.15774.02884

[39] Sigit Haryadi; Dyah Rakhma Ariyanti. (October 2017). The Fairness of Resource Allocation and Its Impact on 5G Ultra-Dense Cellular Network Performance. The 11th International Conference on Telecommunication Systems, Services, and Applications, At Lombok, Indonesia.

[40] Westi Riani; Sigit Haryadi. (2017). CALCULATOR for the Government to make the Fair Policy of Tax Rates. Researchgate. DOI:

10.13140/RG.2.2.18550.50246. Available online at http://sigitharyadi.net/multidicipline/income-tax-rates-calculator-id/

[41] Westi Riani; Sigit Haryadi. (2017). The Method Of Tax Rate Determination Based On Fairness. Prosiding Seminar Nasional SNaPP2017, Bandung, Indonesia.

[42] Haryadi, S., \& Riani, W. (2018, March 12). Telecommunication Competition and Interconnection. Retrieved from osf.io/preprints/inarxiv/7tfqd 